\title{
Teenagers' Decision Making About Abortion As An Action To Terminate Unwanted Pregnancy
}

\author{
Fatya Nurul Hanifa $^{1 *}$, Anjarwati $^{2}$, Herlin Fitriani Kurniawati ${ }^{2}$ \\ ${ }^{1}$ Universitas Aisyiyah Yogyakarta, Student Of Magister Midwifery, Yogyakarta, Indonesia, ${ }^{2}$ Universitas 'Aisyiyah Yogyakarta, \\ Lecturer Of Magister Midwifery, Yogyakarta, Indonesia
}

OPEN ACCESS

ISSN 2548-2246 (online) ISSN 2442-9139 (print)

Edited by: lid Putri Zulaida

Reviewed by: Evi Wahyuntari

*Correspondence:

Fatya Nurul Hanifa

fatyanh2904@gmail.com

Received: 16 Maret 2020

Accepted: 22 Maret 2020

Published: 06 Oktober 2020

Citation:

Nurul Hanifa F, A and Fitriani

Kurniawati H (2020) Teenagers' Decision Making About Abortion As An Action To Terminate Unwanted

Pregnancy.

Midwiferia Jurnal Kebidanan. 6:2. doi: 10.21070/midwiferia.v\%vi\%i.61
Unwanted pregnancy and pregnancy termination generally occurs in adolescents who want to prevent or delay childbirth and have limited access to contraception. Women and girls have unmet contraceptive needs, so that unwanted pregnancies and unsafe abortions are considered normal. The latest data states that $7 \%$ of girls aged 15 to 19 will become pregnant and $2 \%$ of girls in this age group will have an abortion. Decision making for women before carrying out intentional abortions is influenced by several factors including individual level factors namely marital status, education level, economic independence and whether the woman is a victim of rape or incest. Interpersonal factors such as parent and partner support are also found as influences in decision making, because they have social determinants such as religion and social stigma and norms that exist. The aim of this study was to find out how adolescents make decisions about abortion as an end to unwanted pregnancies. The researcher conducted a study by looking at the quality of the study (critical appraisal) in the literature that was eliminated from the inclusion criteria. The main reasons for adolescent girls to have an abortion are socio-economic problems, stress or depression, lack of support from male partners and women's autonomy to make their own decisions regarding termination of pregnancy. Limited sexual knowledge, reproductive knowledge, health information, and lack of access contraception cause unplanned pregnancies, as well as the stigma of losing their opportunity to maintain unplanned pregnancies. These are the main reason women seek abortion services. It is essential to address gender inequality and to promote the fair relationship between powers in order to lead to increase human rights, especially in decision making. It would be also the center of all teenagers' future as well as the fundaments of program plan and policies owned by the government.

Keywords: Decision Making, abortion, adolescence, unwanted pregnancy BACKGROUND The World Health

\section{BACKGROUND}

The World Health Organization (WHO) states that unsafe abortion is a procedure to end unwanted pregnancies by medical or non-medical staff who do not have adequate skills in environment and have not met medical standards (of Reproductive Health et al., 2008). Unwanted pregnancy and pregnancy termination usually occurs in women who want to prevent or delay childbirth and have an access to use contraception. On the women and girls have not contraceptive needs, so that unwanted pregnancies and unsafe abortion claimed as insignificant matter. The latest data states that $7 \%$ girls aged 15 to 19 are pregnant and $2 \%$ girls in this age group 
have an abortion. In 2010, 614,000 girls aged 15 to 19 years old and 11,000 girls aged 14 years old and younger are pregnant (Henshaw, 2015). About 25 million unsafe abortions (45\% of all induction abortions) occur globally (of Reproductive Health et al., 2008). Despite the availability of safe and effective abortion, unsafe abortion still contributes to maternal morbidity and mortality. The majority of maternal deaths due to unsafe abortion occur in low-income environments that women experience low social status combined with legal and social restrictions for sexual and reproductive rights .

In the United States, about $51 \%$ of pregnancies are unintentional and $40 \%$ of unplanned pregnancies end in abortion. However, among girls aged 15 to 19 years old, about $82 \%$ pregnancies are not planned, and about one third of girls who face unwanted pregnancies choose to do abortion Finer and Zolna (2001). The most common reason youth reported to choose abortion is school interruption and / or career and financial issue Singh et al. (2010).

East Africa is a country with the highest level of unsafe abortion, about $18 \%$ of maternal deaths. In Kenya, the abortion with purpose and maternal mortality of unsafe abortion is higher. A new research in Kenya about abortion with purpose is estimated 48 abortions annually in yearly out of 1,000 women of reproductive age, compared with an estimated 34 abortions annually out of 1,000 in East African region Mohamed et al. (185 (2015). Some of other studies have reported that at least one third of maternal deaths in Kenya are due to unsafe abortion Madise (2009) . Due to no reports of definite abortion events, the likelihood of abortion rates and the contribution of unsafe abortion to mortality are much higher Sedgh (2008). Women decision before intentional abortion is influenced by several different reasons Alhassan et al. (April (2016). Individual level factors include marital status, education level, financial independence and whether the woman is a victim of rapist or incest. Interpersonal factors such as parent and partner influence the decision, because they have social determinants such as religion and social stigma and existing norms Gbagbo (2015).

\section{METHOD}

\section{Design review}

In accordance with the objectives and research questions, the literature used in this study was obtained through a comprehensive search system (Comprehensive literature search). The literature search method in this study was carried out for 10 years, namely the period 2008 to 2018 and then identified using electronic databases from PubMed and Science Direct. Database disbursement, scanning, and article screening were carried out independently by researchers. Researchers follow the requirements in fulfilling the inclusion criteria.

\section{Framework}

TABLE 1 | The framework used is PEOS (Population, Exposure / Event, Outcomes, Study Design)

\begin{tabular}{|c|c|c|c|}
\hline Element & Inclusion & Eksclusion & $\begin{array}{l}\text { Ratio- } \\
\text { nale }\end{array}$ \\
\hline $\begin{array}{l}\text { Popula- } \\
\text { tion }\end{array}$ & $\begin{array}{l}\text { Female teenagers who are pregnant or having history of abortion } \\
\text { and not safe abortion experience }\end{array}$ & $\begin{array}{l}\text { Women who have never } \\
\text { been pregnant }\end{array}$ & \\
\hline $\begin{array}{l}\text { Expo- } \\
\text { sure }\end{array}$ & Abortion & & \\
\hline $\begin{array}{l}\text { Compar- } \\
\text { ison }\end{array}$ & Taking decision Experience & & \\
\hline $\begin{array}{l}\text { Study } \\
\text { Design }\end{array}$ & In-depth interview. & & \\
\hline
\end{tabular}

\section{Literature Searching Strategy}

The first step of reference article is a paper as review / systematic review to develop keywords to have a specific paper. Secondly, after getting the keywords then find out the papers in pubmed and science direct database. The keywords used to search for papers in PubMed is ")((((" decision making ") AND abortion) OR" unsafe abortion "OR" induced abortion "AND" unwanted pregnancy ") OR" unplanned pregnancy "AND youth) AND Adolescent "Young women * free full text ${ }^{*} 10$ years old" in science use the same direct keywords. The second step is searching for articles which has reference lists from some articles related to topic. 


\section{Prism Flow Diagram}

Among identified 493 articles, there are 25 articles selected. The next step is article through selection to find the right and complete reference about decision making on abortion, factors and experiences about abortion. The researcher selected the titles and abstracts of all articles used to have inclusion criteria. Full text studies are taken and reviewed independently based on these criteria. Therefore, there are 4 good quality articles for final review. (Tabel 1 )

\section{Critical Appraisal}

The researcher conducted the study by critical appraisal in the literature which was eliminated from the inclusion criteria. This study is used "CASP ". Critical appraisal is used to assess the quality of articles. The assessment chosen to measure the quality of articles is the CASP checklist. At the critical appraisal stage there are 7 articles related to topic of youth decision to abortion. All articles that have been made critical appraisal are qualitative research. After making critical appraisal, selected 4 articles based on the study they have good quality.

\section{Findings}

Based on the results of the analysis of the research conducted, it was found that youth decision-making was influenced by several factors, such as social economic and psychological actors, women's autonomy towards decision making (gender equality), low knowledge about reproductive health and sexuality, and stigma in society.

\section{Prism Flow Diagram}

\section{Critical Appraisal}

The researcher conducted the study by critic

\section{Social, economic and psychological factors}

The study of Loi et al. (2018) state that respondents described their own experiences about decision making before induced abortion. This study shows that the main reasons for young women to have an abortion are socio-economic problems, stress or depression, and lack of support their spouse. Women who are still students and live with their parents show that their parents will not financially support their living and study and raising additional children. Some respondents are guilty and depressed about lying to their spouse and family about pregnancy.

In addition, women are very ashame and self-blame for abortion which considered immoral and inappropriate. Meanwhile, some women said that they decided on an abortion immediately after realizing that they were pregnant, some respondents described when experiencing a lot of stress and opposed what was around them in trying to decide something to do (Kotecha et al., 2012). Some respondents said that the main decision maker in the act of abortion was from their spouse. They pressured the women to end the pregnancy. Almost all women express disagreement with their spouse regarding pregnancy. Some women revealed that they terminate a pregnancy without telling her partner, fear of the consequences that will be happened such as anger, violence and dismissal. Indirectly, this is done because their partner who does not want to responsible for his actions which included in financial issues and social problems that will be faced. In some cases encountered during interviews with respondents, spouse controlled decision-making by arranging unsafe abortion with no consent from women.

Women's autonomy towards decision making ( gender equality)

Based on the analysis, four factors have a negative impact on the decision making process. Lack of women's autonomy to make their own decisions on pregnancy termination. Most women show decide their pregnancies termination mostly taken over by others, sometimes against their will, parents, family members, spouse and service providers of abortion decide it. As shown in the literature, the lack of autonomy in abortion decision-making is related to power and gender inequality (Jejeebhoy et al., 2010).

In one side, power reflects the the power of individuals or groups that impose their will on others, with or without the consent of others. The power of parents / families is observed when they are directly or indirectly affecting their daughters to induce abortion, for example by threatening to dropped them out of the house. Gender inequality is a factor that based on the unbalance happened between men and women.

\section{Lack of knowledge about reproductive health and sexuality}

The study of Jayaweera et, al. Jayaweera et al. (2018) suggested that respondents described various factors that influenced abortion in their society. According to respondents, lack of 
knowledge about sexual and reproductive health information and lack of access to contraceptive services caused unplanned pregnancies to women in society. Various stigma and loss of opportunities for women with unplanned pregnancies, they face as the main reason why women seek and do the abortion. Other barriers are often intertwined with stigma, including the lack of education about safe abortion, the illegality of abortion, and the limited access to health services, fear of abuse from their spouse, and distrust to service providers and health facilities. Respondents reported that they did not know where abortion services were provided (Anwar et al., 2010). They do not know the legal procedures and do not know what their sexual rights are. Lack of knowledge among women contributes the high prevalence of pregnancy termination beside health facilities and it is not legal procedures. Abortion service providers often do not refer clients to health facilities or do not inform legal procedures, creating gaps between legal procedures and practices that stimulate illegal and unsafe abortions. The importance of clarifying and providing information to women and providers of abortion services has become a current regulation and ensures that abortion is available in all circumstances based on the law (Rahman et al., 2011).

\section{Stigma}

The study of Frederico, et al. Frederico et al. (2018) show the various factors that influence respondents to do abortion. They state that the factors are the lack of sexual and reproductive knowledge and health information also lack of access to contraception caused unplanned pregnancies. Respondents in the seven focus groups discussion identified and stated the importance of information and education about sexual and reproductive health and rights in their communities as a way to prevent unplanned pregnancies, especially for youth who were considered socially disadvantaged. Respondents mention the stigma about they will lost opportunity to maintain a unplanned pregnancy and the find the main reasons to seek abortion services. They thought that stigma is a major barrier for women to have safe abortions. Another barrier which is often associated with stigma, including lack of education about safe abortion methods, perceptions of illegal abortions, and limited access to abortion services, also the fear of mistreatment, and distrust of providers and healthcare facilities (Wong, 2012).

Respondents reported that women were highly judged if they were known or suspected of having an abortion. The stigma is most commonly manifested as news that is not yet group as the truth and leads to verbal abuse and even to physical that are viewed as bad in coomunity, also accusations of being involved in sex work or prostitution. Stigma also raises the perception that abortion is the result of infidelity or disloyalty to their spouse, and is contrary to social expectations and about gender equality.

\section{DISCUSSIONS}

Based on the study of 4 journals that have been reviewed, the results obtained that youth in making decisions about abortion to terminate unwanted pregnancies are influenced by several factors and reasons. Economic, social and gender equality factors highly influence women's agency to perceived choices in abortion-related decision making. When women tell their spouse about pregnancy, and then due to their unpreparedness in facing unwanted pregnancies make the main decision-makers named male spouse who insist on pregnancy termination and indirectly refuse to responsible on financial or social even directly by suing women to end pregnancy. The male partner misled the woman, refuse woman decision to keep the pregnancy by arranging unsafe abortions without her consent. In addition, gender-based power relations prevent women from implement their decisions. The power of women's decision about abortion is limited by gender norms and the unbalance power. Friends or sisters referred as trusted sources of information and moral support when undergoing induction of abortion. Meanwhile, sisters are believed to keep the secret about abortion from family, sharing with women who had abortions as their information. Regardless the relationship status, all respondents stated their acknowledgment publicly about the bad impact of abortion, including fear of negative comments, loss of respect in society due to bad stigma, and they will be very isolated.

The stigma of abortion built on injustice and discrimination in society depend on man- 
ner and adjust the rules in society or culture. The perceived stigma refers to the perception that termination of pregnancy will make woman as inferior. Fear of negative judgment condemn participants to express their decisions and experiences in abortion.

Ius constituendum about possible / true abortion should be in a moderate position which means not only allowing abortion based on medical to save the mother's life in an emergency, but also in some cases such as congenital defects in the fetus, women with mental illness, and pregnancy due to rape and incest as emergency cases which is supported both by pro life and pro-choice groups, so that it can be justified from social perspective. Moreover, the regulation of ius constituendum, which is juridically, socially, comparable with law, medical and psychiatry can be justified. The pro-choice and pro-life groups have contradiction principles. Pro-choice supports the legalization of abortion and pro-life against explicit abortion, but the two different groups support emergency case that have been agreed to do abortion.

\section{CONCLUSION}

The lack of financial independence, the absence of social support, and deviations from genderbased family expectations and norms affect decision-making of women on abortion to end unwanted pregnancies. Public ignorance on stigma is influence and place women in situations where abortion happened without their consent. Overcome the gender inequality and promote fair power are needed to improve human rights, especially decision making for all youth future, having government's programs and policies.

\section{REFERENCES}

Alhassan, A. Y., Abdul-Rahim, A., and Akaabre, P. B. (Apri (2016)). European Scientific Journal April 2016 edition vol.12, No.12 ISSN: 1857 - 7881 (Print) e - ISSN 1857- 743195 Knowledge, Awareness And Perceptions Of Females On Clandestine Abortion In Kintampo North Municipality, Ghana. European Scientific Journal 12. doi: 10.19044/esj.2016.v12n12p95.

Anwar, M., Sulaiman, S. A. S., Ahmadi, K., and Khan, T. M. (2010). Awareness of school students on sexually trans mitted infections (STIs) and their sexual behavior: a crosssectional study conducted in Pulau Pinang, Malaysia. BMC Public Health 10, 47-47. doi: 10.1186/1471-245810-47.

Finer, L. B. and Zolna, M. R. (2001). Shifts in intended and unintended pregnancies in the United States. Am J Pub Health 23, 1-9.

Frederico, M., Michielsen, K., Arnaldo, C., and Decat, P. (2018). Factors Influencing Abortion Decision-Making Processes among Young Women. International Journal of Environmental Research and Public Health 15. doi: 10.3390/ijerph15020329.

Gbagbo (2015). Decision-Making for Induced Abortion in the Accra Metropolis. Ghana. African Journal of Reproductive Health 19, 34-42.

Jayaweera, R. T., Ngui, F. M., Hall, K. S., and Gerdts, C. (2018). Women's experiences with unplanned pregnancy and abortion in Kenya : A qualitative study, 1-13. doi: 10. 1371/journal.pone.0191412. PMID: 29370220 ; PMCID: PMC5784933.

Jejeebhoy, S. J., Kalyanwala, S., Zavier, A. J. F., and Kumar, R. (2010).

Kotecha, P. V., Patel, and Sv, M. (2012). VS Reproductive health awareness among urban school going adolescents in Vadodara city. Indian J Psychiatry 54, 344-348.

Loi, U. R., Lindgren, M., Faxelid, E., Oguttu, M., and Klingberg-Allvin, M. (2018). Decision-making preceding induced abortion : a qualitative study of women' s experiences in Kisumu (Kenya), 1-12.

Madise (2009).
Mohamed, S. F., Izugbara, C., Moore, A. M., Mutua, M., Kimani-Murage, E. W., Ziraba, A. K., et al. (185 (2015)). The estimated incidence of induced abortion in Kenya: a cross-sectional study. BMC Pregnancy and Childbirth. doi: https://doi.org/10.1186/s12884-015-0621-1. Published 21 August 2015.

of Reproductive Health, D., Research, and Organization, W. H. (2008). Unsafe abortion: global and regional estimates of the incidence of unsafe abortion and associated mortality in 2008 Sixth edition.

Rahman, A. A., Rahman, R. A., Ibrahim, M. I., Salleh, H., Ismail, S. B., Ali, S. H., et al. (2011). Knowledge of sexual and reproductive health among adolescents attending school in Kelantan. Malaysia. Southeast Asian Journal of Tropical Medicine and Public Health 42, 717-717.

Sedgh, G. (2008). Induced abortion: incidence and trends worldwide from 1995 to.

Singh, S., Sedgh, G., and Hussain, R. (2010). Unintended Pregnancy: Worldwide Levels, Trends, and Outcomes. Studies in Family Planning 41, 241-250. doi: 10.1111/j.1728-4465. 2010.00250.x.

Wong, L. P. (2012). An exploration of knowledge, attitudes and behaviours of young multiethnic Muslim-majority society in Malaysia in relation to reproductive and premarital sexual practices. BMC Public Health 12, 865-865.

Conflict of Interest Statement: The authors declare that the research was conducted in the absence of any commercial or financial relationships that could be construed as a potential conflict of interest.

Copyright (c) 2020 Nurul Hanifa, and Fitriani Kurniawati. This is an open-access article distributed under the terms of the Creative Commons Attribution License (CC BY). The use, distribution or reproduction in other forums is permitted, provided the original author(s) and the copyright owner(s) are credited and that the original publication in this journal is cited, in accordance with accepted academic practice. No use, distribution or reproduction is permitted which does not comply with these terms. 